\title{
Laparoscopic versus open appendectomy: a prospective comparative study
}

\author{
Sumita Pradhan, Yagya Ratna Shakya, Hemant Batajoo, Balram Malla, Hem Nath Joshi, Lok Bikram Thapa, \\ Ram Kantha Makaju.
}

Department of Surgery, Dhulikhel Hospital, Kathmandu University Hospital, Nepal

Correspondence: Sumita Pradhan, Department of Surgery, Dhulikhel Hospital, Kathmandu University Hospital, Nepal

Email : sumiepradhan@gmail.com

\begin{abstract}
Introduction: Appendectomy is one of the most commonly performed surgeries usually done by conventional open method. The role of laparoscopic appendectomy is still not well defined in the literature and although widely practiced it still hasn't gained popularity in Nepal. The aim of this study was to compare the outcomes of laparoscopic versus open appendectomy.

Methods: A prospective study was carried out, between August 2013 and September 2014, involving 216 patients (93 males and 123 females) with a diagnosis of acute appendicitis based on Alvarado score of seven and above. Patients were allocated into two groups where every alternate patient was operated either open or laparoscopically. The groups were compared in terms of operative time, post operative pain, post operative complications and length of hospital stay.

Results: Open appendectomy (OA) comprised of 106 patients and Laparoscopic appendectomy (LA) comprised of 110 patients. Patients' characteristics were similar in both groups. The mean operative time in LA was $42.82 \pm 10.84$ minutes and in OA $37.99 \pm 9.81$ minutes $(\mathrm{p}<0.86)$. Conversion was done in $2.8 \%$ of laparoscopic cases. Mean comparison of postoperative pain by visual analogue scale was low in LA compared to OA $(\mathrm{P}<0.05)$. Mean post operative stay $(3.19 \pm 1.26$ vs $2.75 \pm 0.7$, $\mathrm{p}<0.01)$ and surgical site infection was recorded in 9 patients $(8.5 \%)$ in OA group and $3(2.5 \%)$ in LA group, with p value of 0.06 .
\end{abstract}

Conclusions: Laparoscopic appendectomy is feasible and safe as open procedure with less post operative pain and shorter hospital stay.

Keywords: Acute appendicitis; laparoscopic appendectomy; open appendectomy

\section{Introduction}

Appendectomy is one of the most commonly performed surgeries worldwide. It is commonly done by conventional open method but with progress of laparoscopic surgical procedures, laparoscopic appendectomy is also practiced nowadays. Ever since its initial description by Semm in 1983, laparoscopic appendectomy has struggled to prove its superiority over the open technique. ${ }^{1}$ The concept of minimal surgical trauma, resulting in significantly shorter hospital stay, less postoperative pain, faster return to daily activities has made laparoscopic surgery for acute appendicitis very attractive ${ }^{2}$ but laparoscopic appendectomy has still not become popular in our country. JSSN

\section{Methods}

A prospective study was carried out in the department of Surgery, Dhulikhel hospital from August 2013 to September 2014. All patients admitted with a diagnosis of acute appendicitis and underwent operative procedure were included in the study. Written informed consent was taken. Institutional review board clearance was obtained. Patients were divided into two groups where every alternate case was Open appendectomy (OA - odd number cases) and Laparoscopic appendectomy (LA- as even number cases).

The diagnosis of appendicitis and decision for operation was made if Alvarado ${ }^{3}$ score $\geq 7$. In patients where a clinical 
diagnosis could not be established, abdominal ultrasound was performed.

Patients were excluded if the diagnosis of appendicitis was not established or if they had a history of symptoms for more than 3 days and/or a palpable mass in the right lower quadrant, suggesting an appendicular lump or abscess. Interval appendectomy, appendectomy performed incidental to other procedures, age of the patient $<10$ years and those refusing to participate in the study were not included. Patients with the following conditions were also excluded : history of cirrhosis and coagulation disorders, generalized peritonitis, shock on admission, absolute contraindication to laparoscopic surgery (large ventral hernia, history of previous laparotomy for bowel obstruction, ascites with abdominal distension), contraindication to general anesthesia (severe cardiac and/ or pulmonary disease) and pregnancy.

Prior to the surgery, all the patients received a standard regimen of intravenous antibiotics (injection Ceftriaxone $1 \mathrm{gm}$ and injection Metronidazole $500 \mathrm{mg}$ ). In patients with complicated appendicitis, antibiotics were continued for seven days and modified according to the culture results.

Open appendectomy was performed through Lanz or Grid Iron incision. Following appendectomy the stump was transfixed with an absorbable suture. In the laparoscopic group, pneumoperitoneum was produced by continuous pressure of 10-12 $\mathrm{mmHg}$ of carbon dioxide via a Verres cannula infraumbilically. Following gas insufflation, a 10 $\mathrm{mm}$ trocar for the 30 degree angled laparoscope was placed in the infraumbilical area and two additional trocars, a 10 $\mathrm{mm}$ trocar in the suprapubic area and a third $5 \mathrm{~mm}$ trocar in the left lower abdominal quadrant were introduced under direct visualization. The patient was placed in a Trendelenberg position, with a slight rotation to the left. The appendicular artery was clipped with endoclips and divided while the base of the appendix was ligated with chromic endoloops. The specimen was extracted through the suprapubic port. All specimens were sent for histopathology. Patients were converted from laparoscopic to open appendectomies at the discretion of the surgeon.

The parameters examined in this study included patient's characteristics (age, sex), operation time (from skin incision to wound closure), conversion to open procedure and intraoperative findings (normal, gangrenous or perforated appendix). Postoperative pain was assessed by a visual analogue score. The length of hospital stay and complications were also recorded. Patients were given injection Ketorolac $30 \mathrm{mg}$ eight hourly as the first medication for postoperative pain control for 24 hours along with Tablet Paracetamol 1gm per oral eight hourly once liquid diet was started 4 - 6 hours after the surgery. Gradually the diet was progressed as tolerated. Patients was discharged once there vitals were stable, had good pain control and tolerated soft diet.

Statistical analysis was performed using SPSS statistical software, version 16.0 (SPSS Inc., Chicago, IL). The numerical data was expressed as mean and standard deviation. Independent sample $\mathrm{t}$ tests for parametric continuous variables and chi-square analysis for categorical variables were used. $P$ value of less than 0.05 was considered statistically significant.

\section{Results}

In the above mentioned time period, there were 216 cases of appendectomy with 93 (43.1\%) male and 123 (56.9\%) female cases. They were assigned into two groups, where 106 patients underwent Open Appendectomy (OA) and 110 patients underwent Laparoscopic Appendectomy (LA). Three patients were converted from Laparoscopic to open appendectomy.

Average age and male: female ratio was similar in both groups. Migratory right iliac fossa pain and tenderness were common clinical features, followed by anorexia; nausea and elevated temperature.

\section{Table 1: Patient characteristics}

\begin{tabular}{|c|c|c|c|}
\hline & $\begin{array}{l}\text { Open } \\
\text { appendectomy } \\
(n=106)\end{array}$ & $\begin{array}{l}\text { Lap } \\
\text { appendectomy } \\
(n=110)\end{array}$ & $\begin{array}{l}\text { p } \\
\text { value }\end{array}$ \\
\hline Male & 47 & 46 & 0.70 \\
\hline Female & 59 & 64 & \\
\hline $\begin{array}{l}\text { Age } \\
(\text { Mean } \pm \text { SD) }\end{array}$ & $32.05 \pm 17.04$ & $32.62 \pm 14.45$ & 0.79 \\
\hline $\begin{array}{l}\text { Duration of } \\
\text { complaints }\end{array}$ & $1.69 \pm 0.77$ & $1.77 \pm 0.76$ & 0.62 \\
\hline $\begin{array}{l}\text { Alvarado } \\
\text { score }\end{array}$ & $7.38 \pm 0.97$ & $7.50 \pm 0.85$ & 0.12 \\
\hline
\end{tabular}

The operative time in OA group was 37.99 minutes $(\mathrm{SD}=9.8$ ) while that in LA group was 42.82 minutes $(\mathrm{SD}=10.8)$. The operative time decreased with the increasing experience. Most of the appendices were inflamed while $12.2 \%$ in OA and $6.3 \%$ in LA were gangrenous. Similarly $9.4 \%$ in OA and $4.5 \%$ in LA were perforated appendix. 
Mean comparison of postoperative pain by visual analogue scale, was significantly low in Group LA, compared with Group OA, 24 hours after surgery (Table-3). The hospital stay was $3.19 \pm 2.16$ days in Group OA and $2.75 \pm 0.7$ days in Group LA $(\mathrm{P}<0.01)$. Nine patients $(8.5 \%)$ in Group OA while, $3(2.5 \%)$ patients in Group LA developed postoperative wound infection at 1 week follow up.

\section{Table 3: Post operative outcomes}

$\begin{array}{llll} & & & \text { PA } \\ \text { Pain score } & 5.2 & 4.6 & \text { Value } \\ \text { Length of hospital stay } & 3.19 \pm 2.16 & 2.75 \pm 0.7 & <0.01 \\ \text { Complications } & & & \\ \text { SSI } & 9(8.5 \%) & 3(2.5 \%) & 0.06 \\ \text { Intra abdominal abscess } & 0 & 0 & \\ \text { Respiratory } & 2 & 1 & \\ \text { Bowel obstruction } & 0 & 1 & \end{array}$

\section{Discussion}

First appendectomy was reported by Amayand in 1735 and two hundred years down the line little has changed in management of appendicitis. ${ }^{4}$ Minimally invasive surgery has now revolutionized treatment modalities and thus there has been a paradigm shift in the way we manage our patients today. The concept of minimal surgical trauma, leading to significantly shorter hospital stay, less postoperative pain, faster return to daily activities ${ }^{5}$ has made laparoscopic surgery for acute appendicitis a very attractive package.

Laparoscopic appendectomy has been considered to be the procedure of choice in patients with acute appendicitis in a randomized comparison with open appendectomy, ${ }^{6}$ but its role has still not been well defined and it still struggles to prove its superiority. Only few studies have been conducted in Nepal and thus local data on this is scarce.

The mean operative time in our study was around 5 minutes longer in laparoscopic group. Significant variations have been shown in various controlled studies. Preliminary studies $^{7}$ have shown significantly longer operative times for laparoscopic appendectomy. Inexperience of the surgeons with the new technique and thus a longer learning curve may have contributed to the longer duration of the operation in the early studies. While the later studies revealed no difference with duration as less as 2 minutes. $^{8}$

Operative time depends on experience of the surgeon and competence of the operating team, ${ }^{9}$ with increasing experience the operative time also decreases significantly. Our institution has been doing lap appendectomy since past seven years and all surgeons involved in this study had minimum of one year experience doing laparoscopic operations prior to the start of the study and that might explain the similar operative time in two groups.

The rate of conversion is variable in various studies. Variety of reasons has been associated like patients, surgeons or technical factors. ${ }^{10}$ The conversion rate in our study was $2.8 \%$ and the main reasons for conversion were due to lump and adhesions. Lower conversion rate (0-3.3\%) have been reported. ${ }^{11}$

One of the reported advantages of laparoscopic appendectomy is less post operative pain. A meta analysis from Pakistan ${ }^{2}$ showed that LA results in significantly less post operative pain, shorter hospital stay and quick resumption to work. The pain score was similar in first 6 hours and this may be due to effect of spinal anesthesia in open group. The other factor would be because of discomfort due to gas insufflation while creating pneumoperitoneum in lap group. Pain score at 24 hours were significantly low for the laparoscopic group. However the total number of parenteral doses of narcotics or the number of doses of oral analgesics used between the two groups was not calculated and this might have created some bias in our study.

Mean hospital stay was less (2.75 \pm 0.7 days) for laparoscopic group compared to open $(3.19 \pm 2.16$ days) $(\mathrm{P}<0.01)$. A study from Nepal ${ }^{12}$ also showed significant decrease in the length of hospital stay in patients undergoing LA $(p<0.001)$, which is consistent with the findings of other studies. ${ }^{13-14}$

In accordance with other studies, ${ }^{2,12}$ there was fewer wound infection in LA group $2.5 \%$, with the post operative complication of $8.5 \%$. In a study by Tate et al. they highlighted the difference in wound complication rates as a major benefit of laparoscopic appendicectomy. ${ }^{15}$ However, there were three cases of readmission in our study. One each, in both groups for SSI requiring intravenous antibiotics. Third case was in LA group for bowel obstruction, who had to undergo exploratory laparotomy for adhesions. All 3 patients had an uneventful recovery.

Our study had some limitations. We could not assess cost analysis as the cost for both open and laparoscopic appendectomy is same in our hospital. Our follow-up was limited to 6 weeks postoperatively and long term complications were not evaluated. Sample size though adequate, we were not able to see the statistical significance of some of the potential variables like pain score and length 
of hospital stay. More studies are warranted from Nepal regarding this context.

The popularity of laparoscopic cholecystectomy has opened the floodgates for laparoscopy in surgery. The rate of LA has increased since it was first started but it is still far from attaining the status of "Gold standard". But one should always think lap surgery and open as being complimentary to each other. Minimal access surgery requires skills and technical knowledge and thus surgeons should perform procedure with which they are more comfortable with. With widely available trainings and documented benefits of LA, this procedure is slowly gaining acceptance in developing countries like Nepal and waiting to make its mark in the surgical fraternity.

\section{Conclusion}

Laparoscopic appendectomy is feasible and safe as open procedure with less post operative pain and shorter hospital stay.

\section{References}

1. Semm K. Endoscopic appendectomy. Endoscopy. 1983; 15: 59-64.

2. Ioannis Kehagias, Stavros Nikolaos Karamanakos, Spyros Panagiotopoulos, Konstantinos Panagopoulos, Fotis Kalfarentzos.Laparoscopic versus open appendectomy: Which way to go? World J Gastroenterol 2008; 14: 4909-14.

3. Alvarado A: A practical score for the early diagnosis of acute appendicitis. Ann Emerg Med 1986, 15:557-64.

4. Creese PG. The first appendectomy. Surg Gynecol Obstet. 1953;97:643

5. Sauerland S, Lefering R, Neugebauer EAM. Laparoscopic versus open surgery for suspected appendicitis. The Cochrane Database of Systematic Reviews 2002, Issue 1. Art. No.: CD001546. DOI: 10.1002/14651858.CD001546.

6. Frazee RC, Roberts JW, Symmonds RE, et al. A prospective randomized trial comparing open versus laparoscopic appendicectomy. Ann Surg 1994; 219:725-31.

7. Temple LK, Litwin DE, McLoid RS. A meta-analysis of laparoscopic versus open appendectomy in patients suspected of having acute appendicitis. Can J Surg. 1999; $42: 377-83$
8. Minutolo, Vincenzo, et al. "Outcomes and cost analysis of laparoscopic versus open appendectomy for treatment of acute appendicitis: 4-years experience in a district hospital." BMC surgery 14.1 (2014): 1.

9. Chung RS, Rowland DY, Li P, Diaz J. A meta-analysis of randomized controlled trials of laparoscopic versus conventional appendectomy. Am J Surg 1999; 177:250-6.

10. Liu SI, Siewert B, Raptopoulos V, Hodin RA. Factors associated with conversion to laparotomy in patients undergoing laparoscopic appendectomy. J Am Coll Surg. 2002; 194:298-305.

11. Martin LC, Puente I, Sosa JL, et al. Open versus laparoscopic appendectomy. A prospective randomized comparison. Ann Surg. 1995; 222:256-61.

12. Batajoo H, Hajra NK. Laparoscopic versus open appendectomy in acute appendicitis. J Nepal Health Res Counc 2012; 10:239-42.

13. Chiarugi M, Buccianti P, Celona G, Decanini L, Martino MC,Goletti O, et al. Laparoscopic compared with open appendectomy for acute appendicitis: a prospective study. Eur J Surg. 1996; 162:385-90.

14. Lujan Mompean JA, Robles Campos R, Parrilla Paricio P, SoriaAldeo V, Garcia Ayllon J. Laparoscopic versus open appendicectomy: a prospective assessment. Br J Surg. 1994; 81:133-5.

15. Tate JJ. Laparoscopic appendectomy. Br J Surg. 1996 Sep; 83(9):1169-70. 